\title{
DERECHO A LA EDUCACIÓN Y LIBERTAD DE ENSEÑANZA
}

\author{
Carlos Peña \\ Universidad Diego Portales \\ Universidad de Chile
}

\begin{abstract}
RESUMEN: Este artículo explora algunos antecedentes históricos y conceptuales a fin de precisar qué tipo de relación debería ser establecida entre la libertad de enseñanza y el derecho a la educación. De acuerdo al autor, en la tradición legal chilena la libertad de enseñanza ha tenido preeminencia frente al derecho a la educación y ha sido concebida al modo de un derecho subjetivo estrictamente individual. Sin embargo, y de acuerdo con el debate entre Alfred Marshall y T.H. Marshall —el economista y el sociólogo, respectivamente-, el derecho a la educación debe ser concebido como un derecho social, aunque este tipo de derechos tienen la función de legitimar la estratificación social fundada en el mérito. Siendo así, se trata de un derecho que no alcanza a todo el sistema educativo.

Palabras Clave: libertad de enseñanza, derecho a la educación, derecho social, mérito, sistema educativo, Alfred Marshall, T.H. Marshall.
\end{abstract}

RECIBIDO: octubre 2015; ACEPTADO: diciembre 2015.

Carlos Peña. Abogado y doctor en filosofía por la Universidad de Chile. Profesor asociado de esa institución. Rector de la Universidad Diego Portales. Sus más recientes publicaciones son Estudios sobre Rawls (Madrid: Coloquio Jurídico Europeo, 2011) e Ideas de perfil (Santiago: Hueders, 2015). Email: carlos.pena@udp.cl. El autor agradece los comentarios que le hicieron llegar los árbitros anónimos de Estudios Públicos. 


\section{RIGHT TO EDUCATION AND FREEDOM TO TEACH}

ABSTRACT: This article explores some historical and conceptual antecedents to precise what kind of relationship should be established among freedom to teach, on the one hand, and right to education on the another. According to the article, in the chilean legal tradition the freedom to teach have had a preeminence over right to education and the former has been conceived like a subjective right, similar to property right. However, and according to debate between Alfred Marshall and T.H. Marshall, the right to education should be conceived like a social right, notwithstanding a social right has the function to legitimate, and not delete, the meritocratic social stratification. In conclusion, the right to education conceived like a social right reaches only a part of the educational system.

KEYwords: freedom to teach, right to education, social right, merit, educational system, Alfred Marshall, T.H. Marshall.

RECEIVED: October 2015; ACCEPTED: December 2015.

\section{E 1 derecho a la educación y la libertad de enseñanza poseen una particular importancia en el debate constitucional contemporáneo.} $\mathrm{Su}$ importancia deriva del hecho de que las demandas relativas a educación, que Chile ha experimentado desde el año 2006 y hasta la fecha, han sido las detonantes de un fenómeno parecido al que Bruce Ackerman denomina "momento constitucional", uno de esos raros lapsos en la vida de los países en que los compromisos públicos que les subyacen son llamados a capítulo, a fin de verificar si están o no a la altura de los tiempos y de las expectativas de los ciudadanos. ${ }^{1}$ Chile está hoy en uno de esos momentos en que el consenso parece haberse acabado y es necesario darse a la tarea de construir reflexivamente uno distinto. Ferdinand Tönnies, uno de los clásicos de la sociología, observó, a fines del siglo XIX, que el consenso es silencioso y donde él existe la palabra se retira. ${ }^{2}$ Pues bien, el hecho de que hoy en Chile estemos debatiendo sobre las bases de la convivencia, explicitando en palabras lo que anhelamos y lo que tememos en materia del derecho a la educación y la

${ }^{1}$ Bruce Ackerman, We the People: Transformations, vol. 2 (Cambridge, Mass: Harvard University Press, 1998).

${ }^{2}$ Ferdinand Tönnies, Gemeinschaft und Gesellschaft (1887), traducido por José Rovira Armengol como Comunidad y sociedad (Buenos Aires: Losada, 1947), 42 . 
libertad de enseñanza, es una muestra de que el consenso, que según Tönnies caracteriza a las comunidades, ya se ha roto y no queda más que hacer el esfuerzo de erigir otro en su lugar.

Pero el consenso en condiciones modernas no es espontáneo - no brota naturalmente de una tradición compartida-, sino que es reflexivo, supone identificar los puntos de vista en juego en la vida social buscando un punto más abstracto que permita conciliarlos. Ello es especialmente así en materia educativa. Mediante la educación, las sociedades intentan, siquiera en parte, transmitir a las nuevas generaciones lo que Durkheim llamaba una conciencia moral. ${ }^{3} \mathrm{Y}$ como en condiciones modernas esa conciencia moral está atravesada por la diversidad, la búsqueda de un consenso reflexivo y superpuesto parece imprescindible. Y para orientar esa búsqueda puede ser útil, al menos como inicio, responder tres preguntas: una descriptiva, otra conceptual y una tercera, normativa.

La pregunta descriptiva (I) inquiere por la relación que en la historia legal chilena han tenido el derecho a la educación y la libertad de enseñanza. Suele creerse que la particular relación que esos derechos poseen hoy - consistente en que el primero se subordina al segundoes fruto de una imposición ideológica de la dictadura, de una ideología neoliberal preocupada ante todo de configurar un mercado de proveedores educativos entre los que las familias pudieren escoger de acuerdo a su renta. Esta visión, como se verá, no es del todo fidedigna y constituye, en verdad, una exageración retórica de las que son habituales en la lucha política por reconfigurar las instituciones. Un sencillo vistazo histórico muestra, en cambio, que la semilla neoliberal no habría fructificado si en el sistema educativo chileno no hubieran existido desde antiguo algunos dispositivos institucionales — provisión mixta, incluida aquella con fin de lucro, subsidios a la demanda en razón de la asistencia - que ese punto de vista promueve. Tomar conciencia de esas características es muy importante, porque las valoraciones presentes de las instituciones dependen, al menos en parte, de su trayectoria.

La pregunta conceptual (II), por su parte, exige dilucidar cómo han de concebirse el derecho a la educación y la libertad de enseñanza. En

${ }^{3}$ Emile Durkheim, La educación moral (Buenos Aires: Losada, 1997), 25 y ss; compárese con A.K.C. Ottaway, "The Educational Sociology of Émile Durkheim", The British Journal of Sociology 6, n. ${ }^{\circ} 3$ (1955): 216. 
el debate que se lleva a cabo en Chile - y que se ha sostenido de manera explícita desde hace ya ocho años- este problema se ha planteado en torno a si la educación es o no un derecho social. Concebir a la educación como un derecho social permitiría, suele afirmarse, cambiar las concepciones subyacentes al sistema educativo. Ello parece ser verdad, a condición de no olvidar que la función de los derechos sociales es la de legitimar un orden meritocrático. La concepción de los derechos sociales, como es sabido, se debe en la literatura sociológica a T.H. Marshall, quien la formuló como un principio de igualdad cuya función era, paradójicamente, legitimar la estratificación social erigida sobre el mérito. Siendo así, parece obvio que dichos derechos no pueden extenderse sin más a la educación superior.

La pregunta institucional (III), a su vez, exige esclarecer a qué tipo de diseño institucional conducen las conclusiones que se alcancen en los dos apartados precedentes.

En lo que sigue se intenta responder, de modo introductorio, cada una de esas tres preguntas.

\section{I. ¿CUÁL HA SIDO LA TRAYECTORIA HISTÓRICA DEL DERECHO A LA EDUCACIÓN Y LA LIBERTAD DE ENSEÑANZA?}

Para saberlo puede resultar útil recordar un famoso incidente.

El año 1872, don Abdón Cifuentes, quien era entonces ministro de Instrucción Pública, dictó un decreto en el que se permitía a las escuelas privadas tener sus propios examinadores, escapando así a la tutela de la Universidad de Chile, la que hasta ese momento certificaba los exámenes en cumplimiento del principio del Estado docente que, si bien de manera tímida, había consagrado la Constitución de 1833. Por esas fechas había en Chile 706 escuelas públicas y 401 escuelas privadas, apenas el 10 por ciento de las que existen hoy, y entre ellas estaba La Purísima, un colegio pagado que presentó una lista de alumnos aprobados por examinadores que, según denunció Miguel Luis Amunátegui, no existían y nunca habían sido llamados a presenciar las pruebas. El colegio La Purísima, a pesar de su nombre, era una simple apariencia, sostenida por un timador que poco menos que vendía los certificados. El escándalo, que tomó rápidamente el nombre de "la feria de los exámenes", puesto que pronto se supo que había otros colegios en la 
misma situación, encadenó los incidentes que obligaron a renunciar a Abdón Cifuentes; motivó una toma violenta del Instituto Nacional por parte de los estudiantes; forzó la salida de Barros Arana de este último establecimiento; y dio, en fin, lugar a un intenso debate para reformar el sistema escolar. ${ }^{4}$

El incidente revela que el caso de la Universidad del Mar - que hace poco escandalizó a la opinión pública chilena, y que al igual que el anterior acabó en la salida de un ministro, dio nuevos impulsos a las tomas de colegios y alimentó el anhelo de reformas - no fue ni el primero ni el único de esta índole que ha ocurrido entre nosotros, aunque lo significativo es que, a pesar de que entre ambos media más o menos un siglo y medio, poseen la misma inquietante fisonomía.

Cuando las cosas se repiten —enseñan Hegel y Freud - es porque existe una estructura subyacente que lo produce. En el caso del colegio La Purísima y el de la Universidad del Mar esa estructura subyacente - la causa solapada del fenómeno - la constituye la particular relación que, en la historia legal chilena, desde la Carta del 33 a la del 80, sin que la del 25 haya sido una excepción, han poseído el derecho a la educación, por una parte, y la libertad de enseñanza, por la otra. En la Carta de 1833 se consagró lo que ya entonces se llamaba el principio del Estado docente, según el cual la educación pública era una ocupación preferente del Estado; pero al mismo tiempo se estableció, el año 1871, la libertad de enseñanza, concebida como el derecho de los particulares a fundar establecimientos de educación de toda índole, los que, ya entonces, podían recibir subsidios públicos. Sarmiento, en su obra sobre educación popular de 1849, promovió ese diseño, que él mismo había, por lo demás, observado en el sistema escolar norteamericano. ${ }^{5}$ Y Jorge Huneeus Zegers, el gran constitucionalista del siglo XIX, agregaba que

${ }^{4}$ Francisco Antonio Encina, Historia de Chile. Desde la prehistoria hasta 1891 (Santiago: Nascimento, 1970), tomo XV, 264 y ss; Abdón Cifuentes, Memorias (Santiago: Nascimento, 1933) tomo II, capítulos XVII a XIX; Amanda Labarca, Historia de la enseñanza en Chile (Santiago: Universitaria, 1939), 158; Diego Barros Arana, Mi destitución. Apuntes para la historia del Instituto Nacional (Santiago: Imprenta El Ferrocarril, 1873).

${ }^{5}$ Domingo Faustino Sarmiento, De la educación popular (Santiago: Biblioteca Fundamentos de la Construcción de Chile, 2009), citado en Ana María Stuven, "Estado docente y libertad de enseñanza: el conflicto por el control del espacio público chileno en el siglo XIX”, en El conflicto de las universidades: entre lo público y lo privado, eds. José Joaquín Brunner y Carlos Peña (Santiago: Ediciones UDP, 2011), 88. 
ello parecía inevitable dados los vínculos entre la libertad de enseñanza y la libertad de trabajo.

Las aparentes inconsistencias de esas reglas no son el resultado de un error jurídico, sino la simple muestra de una dinámica social.

$\mathrm{Y}$ es que la historia de la educación chilena muestra lo que Margaret Archer, en sus estudios sobre los orígenes sociales de los sistemas educativos, ha subrayado una y otra vez. La fisonomía de la educación, explica, suele ser el producto político de luchas de poder. ${ }^{6}$ Ella lleva inscritas las concesiones, los logros, los avances y retrocesos del conflicto a cuya sombra se origina. ¿Significa eso que entonces el sistema educativo está cortado al antojo del grupo más poderoso? Por supuesto que no, agrega, puesto que en la educación siempre hay factores estructurales que constriñen el diseño y su ejecución. La historia educacional se explica así como el resultado de una mezcla entre agencia y estructura. Los actores disputan el campo educativo $\mathrm{y}$, al resolver esa disputa, convienen soluciones de compromiso que moldean la cultura y definen así las posibilidades y límites de las reformas posteriores. Por eso puede afirmarse que, más que otras áreas de la vida social, el campo educativo es dependiente de su trayectoria (path dependence). Es lo que ocurrió en Chile y que se puso de manifiesto con particular elocuencia hacia 1920, cuando se alcanzó la Ley de Instrucción Primaria Obligatoria. Se enfrentaron allí el principio familiar, por una parte, y el estatal, por la otra. El primer principio favorecía la transmisión de la herencia y el capital cultural, en tanto el otro prefería borrar, por decirlo así, todo vestigio de la cuna igualando a los niños en la misma experiencia cognitiva. Esta oposición entre la familia y el Estado, que se repite una y otra vez desde muy antiguo, ${ }^{7}$ entrecruza la historia de la educación chilena, desde el siglo XIX al XX. La fisonomía del sistema educativo chileno puede ser descrita como una solución de compromiso entre ambos principios; aunque, por razones al comienzo estructurales pero más tarde cultura-

${ }^{6}$ Margaret Archer, Social Origins of Educational Systems (Nueva York: Routledge, 2013), Kindle edition, location 489.

${ }^{7}$ Aparece, desde luego, en Platón (República, 461c), quien advirtió que la única forma de alcanzar la igualdad era separando a los niños de la familia a la que pertenecían, y reaparece en Antígona, en la forma en que la presenta Hegel (Fenomenología del espíritu, $\mathrm{V}, \mathrm{c}, \mathrm{a}$.), como un conflicto entre obedecer el interés de la ciudad o el interés familiar. 
les, acabó teniendo primacía la libertad de enseñanza, como veremos enseguida.

La Carta de 1833, por ejemplo, en su artículo 12, introducido el año 1871, garantizaba la libertad de enseñanza, que confería a los padres el derecho de educar a sus hijos de la manera que juzgaran conveniente, incluida, por ejemplo, la posibilidad de formarlos simplemente en el hogar. La libertad de enseñanza excluía, pues, la obligatoriedad de la educación formal. Se consideró también que la libertad de enseñanza incluía el derecho de fundar establecimientos educativos particulares, y a pesar de que se confería a la Universidad de Chile el deber de certificar esos estudios, la regla se eludió mediante un decreto de Abdón Cifuentes, quien, el año 1872, permitió que los establecimientos particulares certificaran sus propios estudios (la regla, como se recordó ya, condujo a la renuncia de Abdón Cifuentes pues debió asumir la responsabilidad por el asunto de La Purísima). ${ }^{8}$

Esa regla - la regla del artículo 12 que consagraba la libertad de enseñanza - coexistía con el principio del Estado docente que establecía el artículo 153, según el cual "la educación pública — no toda la educación, sino sólo la pública, de manera que la regla era un perfecta tautología- es una atención preferente del gobierno". El artículo siguiente establecía la creación de una superintendencia a cuyo cargo estaría el plan nacional de educación elaborado por el Congreso. Jorge Huneeus, en su obra clásica sobre la Constitución de 1833, observa que ese principio del Estado docente está en verdad subordinado a la libertad de enseñanza y ésta, por su parte, vinculada con la libertad de trabajo. De ahí entonces que todas las facultades de esa superintendencia sólo se extienden a la educación costeada por el Estado; en el resto del sistema educativo, explica Huneeus, el Estado sólo tiene derecho de policía, pero no la facultad de incidir en el contenido de lo que se enseña:

El Estado docente es, por consiguiente, una necesidad de primer órden, reconocida i ratificada por diferentes preceptos de la Constitucion. Su existencia no se opone en manera alguna a la libertad de enseñanza, asegurada a todos los habitantes de la República por el art. 12. I por esto es que la lei de 1879 reserva al Consejo de Instruccion, en su art. $6^{\circ}$, la superintendencia constitucional sobre

${ }^{8}$ Labarca, Historia de la enseñanza, 158. 
este ramo del servicio, solo respecto de la enseñanza costeada por el Estado; por esto es que asegura en el $3^{\circ}$ a toda persona natural $o$ jurídica, sin otras excepciones que las mui contadas que menciona su art. $4^{\circ}$, i que reclama imperiosamente la moral pública, el derecho de fundar establecimientos de instruccion i de enseñar pública o privadamente cualquiera ciencia o arte, sin sujecion a medida alguna preventiva ni a métodos o testos especiales; i es por esto, finalmente, que en el inciso $8^{\circ}$ de su art. $9^{\circ}$, limita la inspeccion del Consejo sobre los establecimientos privados de instruccion secundaria i superior, solo a las atribuciones de vijilancia i de policía que se refieran a la moralidad, hijiene i seguridad de los alumnos i empleados, o sea únicamente en los tres primeros casos en que el art. 151 de la Constitucion limita la libertad del trabajo. ${ }^{9}$

Se instaló así en la tradición constitucional desde muy temprano la posibilidad de que se desarrollaran empresas educacionales financiadas íntegramente por las familias.

Sobre la base de esos preceptos, se dictó la Ley de Instrucción de 1879. En esta ley se compatibiliza la libertad de enseñanza (entendida como el derecho de los padres a educar a sus hijos y el de los particulares de fundar establecimientos que escapan al control estatal, salvo en cuestiones de policía) con el derecho a la educación concebido como un sistema educativo costeado por el Estado y entregado a su control.

La disputa de esos dos derechos continúa entre los años 1900 y 1920. En términos de la dinámica que detecta Archer, se trata de un largo conflicto relativo a quién tiene en definitiva la autoridad educacional, si acaso el Estado o las familias. Éste es el proceso que condujo a la Ley de Instrucción Primaria Obligatoria de $1920 .{ }^{10} \mathrm{Su}$ origen se encuentra en un proyecto, finalmente desechado, que presentó en los inicios el senador Bannen. La explicación de motivos de Bannen da una muestra de la primacía que, a pesar de todos los empeños, tiene todavía, en la primera mitad del siglo XX, la libertad de enseñanza: la instrucción obligatoria tiene por objeto suplir, de manera subsidiaria, la

9 Jorge Huneeus, La Constitución ante el Congreso o sea comentario positivo de la Constitución Chilena (Santiago: Imprenta de Los Tiempos, 1880), segunda parte, 393 y 394. Se conservan ortografía y cursivas del original.

${ }^{10}$ Véase Sol Serrano, Macarena Ponce de León y Francisca Rengifo, eds., Historia de la educación en Chile (1810-2010) (Santiago: Taurus, 2012), tomo II, 31 y ss. 
voluntad de las familias que por desidia o por desgracia no son capaces de estar a la altura:

Con el fin de disipar cualquiera duda, el diputado alega que (su) propuesta tenía aplicación solamente en "nuestro bajo pueblo". Sus disposiciones, continúa, "no llegarán a afectar jamás a nuestras clases cultas, ni aun a nuestras clases menos elevadas que tengan hábitos de moralidad y de orden social". Tampoco podía prestarse para propaganda de cualquiera especie, pues sólo se trataría de inculcar los "conocimientos elementales de instrucción"; es decir, aquello que es "deber humanitario y exigencia de la civilización moderna proporcionar a todos nuestros conciudadanos. ${ }^{11}$

Darío Salas expresa de manera más concisa el problema y la solución. "¿Cómo vencer, ahora - se pregunta — la ignorancia, la desidia y el egoísmo de los padres?”. Y responde: “La experiencia de los países cultos, uniforme, y ya larga, (...) nos muestra que a la consecución de ese objetivo no se adapta sino a un medio: la compulsión, reglamentada y sancionada por la ley". ${ }^{12}$

En fin, Valentín Letelier, en su Filosofía de la educación, es quien racionaliza mejor ese conflicto, presentándolo como uno en el que se enfrenta una orientación egoísta de la educación, que estaría inspirada, dice Letelier, en Spencer y el mercado, con otra más social, de inspiración durkheimiana. La educación, explica Letelier,

es el medio de que la sociedad se vale para transmitir de una generación a otra sus ideas, sus sentimientos, sus hábitos, sus virtudes y sus vicios. (...) cualesquiera fueren las dificultades inherentes a la aplicación de este principio, él se debe mantener en abstracto como absolutamente indispensable para conseguir el propósito de la enseñanza. ${ }^{13}$

${ }^{11}$ Citado por José Joaquín Brunner, "La república educacional 1910-2010”, en El Chile del bicentenario, coord. Maximiliano Figueroa y Manuel Vicuña (Santiago: Ediciones UDP, 2008), 29. El texto de Brunner examina la evolución del sistema escolar entre las disputas asociadas a la ley de 1920 y las actuales, mostrando su sorprendente parecido.

12 Darío Salas, El problema nacional (Santiago: Universo, 1917), 43.

13 Valentín Letelier, Filosofía de la educación (Santiago: Cervantes, 1912), 173. 
¿Cuál fue el resultado transitorio de esa disputa ideológica? ${ }^{14}$

El resultado (transitorio, como digo, porque, como lo muestra la extraña contemporaneidad de las palabras de Letelier, el problema sigue en el subsuelo de nuestra cultura pública) fue un sistema de provisión mixta con predominancia estatal. Los proveedores privados, por su parte, podían serlo enteramente financiados por las familias o mediante subsidios estatales en proporción a la asistencia (un adelanto, sin duda, del sistema de vouchers que propondrá Friedman el año 1952).

Un breve vistazo a la ley de 1920 permite mostrar que allí se asentó el sistema de provisión mixta que hasta hoy resulta predominante en Chile.

Esa ley, en efecto, reconoció el derecho de los privados a impartir educación primaria general o vocacional mediante establecimientos sostenidos "por instituciones de beneficencia, por sociedades de cualquiera clase, por particulares o con emolumentos de los padres de familia" (Art. 44). Se impuso la obligatoriedad de la educación, pero al mismo tiempo se permitió a los privados ofrecer instrucción reconocida por el Estado, ya sea mediante emprendimientos personales o a través de centros educativos de organizaciones con y sin fines de lucro o sostenidos por la renta familiar.

El financiamiento de los proveedores públicos, por su parte, se efectuó mediante subsidios en base a la asistencia media de los estudiantes (artículo 42). La misma subvención se hacía luego extensiva a los establecimientos de educación privada, cualquiera fuese su estatuto jurídico, siempre que reunieran algunos requisitos como ser gratuitos; ofrecer como mínimo la enseñanza determinada por el Estado, sin obligación de enseñar la doctrina cristiana; funcionar en un local higiénico; tener una asistencia media de treinta y cinco alumnos por lo menos en los distritos urbanos y quince por lo menos en los distritos rurales; y funcionar por lo menos cuatro horas diarias durante 180 días en el año (Art. 44).

De ahí en adelante - durante todo el transcurso del Estado de compromiso y hasta 1970 - puede afirmarse que ese principio mixto que consolidó la ley de 1920 se mantuvo, aunque la reforma educacional de Frei Montalva procuró alcanzar la predominancia estatal dentro del sistema. La reforma de 1971 mantuvo el carácter mixto del sistema, or-

14 Sobre esta evolución, debe consultarse Brunner, "La república educacional", 48 y ss. 
ganizado ahora como un sistema nacional de educación, a pesar de que se previó, en el número 10, número 16, el deber del Estado de promover el goce de los derechos económicos, sociales y culturales. Finalmente, en la dictadura la provisión mixta se mantuvo, la provisión pública se transfirió a las municipalidades, se diseñó un sistema de vouchers (suprimiendo los subsidios a la oferta con base histórica que entonces también existían), se cambiaron las bases de la profesión docente y se estableció un sistema nacional de evaluación. Como es fácil observar, los principios subyacentes a la reforma educacional de la dictadura venían ya desde el siglo XIX y paradójicamente se instalaron en $1920{ }^{15}$

Así se configuró el sistema que, en sus líneas fundamentales, hasta hoy se mantiene.

\section{II. ¿CÓMO DEBEN CONCEBIRSE EL DERECHO A LA EDUCACIÓN Y LA LIBERTAD DE ENSEÑANZA?}

Si acabamos de examinar cómo, en los hechos, se han concebido en la historia legal chilena esos derechos, lo que cabe preguntarse ahora es cómo debieran ser concebidos en una futura reforma. Para dilucidar este problema es inevitable revisar si acaso uno de esos derechos -en especial el derecho a la educación- posee o no un carácter social.

En la literatura legal, la idea de derechos sociales ha solido discutirse.

Un derecho, en el sentido jurídico de la expresión, equivale a un título que confiere un poder para reclamar, coactivamente si es necesario, una determinada prestación. ${ }^{16}$ El paradigma de un derecho (según una

${ }^{15}$ Artículo 1, números 13 y 14 del Acta Constitucional número 3.

${ }^{16}$ Lo que Kelsen llama un derecho subjetivo en un sentido técnico, véase Hans Kelsen, Teoría pura del derecho, traducido por Roberto J. Vernengo (México: Porrúa, 1991), 147. Desde luego, ese sentido no agota los usos de la palabra derecho o de las expresiones "tengo derecho a". Al respecto, véase el famoso análisis de Wesley Newcomb Hohfeld, "Some Fundamental Legal Conceptions as Applied in Judicial Reasoning", The Yale Law Journal 23 (noviembre, 1913): 16-59; véase también W.N. Hohfeld, "Fundamental Legal Conceptions as Applied in Judicial Reasoning", The Yale Law Journal 26 (junio, 1917): 710-770. En el primero de esos textos, Hohfeld mostró que la palabra derecho puede ser usada para designar que otro tiene un deber correlativo a mi respecto (32); o que tengo la potestad de modificar una relación normativa (44); o que soy inmune a la voluntad o la potestad de otro (55); o que soy libre para ejecutar una acción o dejar de ejecutarla (36). 
tradición que posee defensores tan ilustres como Locke o Kant $)^{17}$ sería la propiedad que concede una facultad exclusiva y excluyente sobre algún bien escaso. Ahora bien, como los derechos sociales equivaldrían a títulos para reclamar del Estado determinadas prestaciones, hay quienes les niegan el carácter de derecho puesto que carecerían de la posibilidad de exigencia coactiva, su cumplimiento dependería del nivel de desarrollo económico y su aceptación importaría trasladar a la esfera judicial problemas de política pública o de asignación de recursos fiscales. Parece obvio, por supuesto, que si un derecho se concibe sobre la base de la propiedad (así nació, por lo demás, la idea de derecho subjetivo en el sentido moderno de esa expresión) es difícil que la pretensión de que el sistema educativo se organice de determinada forma pueda ser llamado derecho.

Pero hay un sentido, como se verá de inmediato, en que esa expresión referida al sistema educativo puede resultar útil.

Para mostrarlo hay que dar un breve rodeo por la historia de las ideas y revisar el debate entre Alfred Marshall, uno de los fundadores de la economía neoclásica y uno de los responsables de extender su método al examen de casi todas las actividades humanas, y T.H. Marshall, sociólogo, quien creyó que en el naciente Estado de bienestar se anidaba un principio transformador de todo el edificio social.

Ambos discutieron (es un decir, puesto que cuando T.H. Marshall escribió su famoso ensayo sobre ciudadanía y clase social habían pasado 25 años desde la muerte de Alfred) sobre el lugar de la igualdad en la sociedades y cómo ella se alcanzaría. Y ambos también pusieron atención al contexto y al papel de los precios. Son así un ejemplo para

${ }^{17}$ En la literatura se discute, sin embargo, si acaso la noción de derecho subjetivo (como un título que entrega a la voluntad individual la disposición de un cierto recurso) guarda o no continuidad con la tradición medieval o si es genuinamente moderna. Algunos, como Michel Villey, en Estudios en torno a la noción de derecho subjetivo (Valparaíso: Ediciones Universitarias de Valparaíso, 1976), señalan que el concepto de derecho subjetivo supuso un quiebre radical con la tradición medieval; otros, como Brian Tierney, en Liberty and Law. The Idea of Permissive Natural Law, 1100-1800 (Washington DC: Catholic University of America Press, 2014), afirman que, en cambio, hay continuidad. Puede consultarse también Adam Seagrave, "How Old Are Modern Rights? On the Lockean Roots of Contemporary Human Rights Discourse", Journal of the History of Ideas 72, n. ${ }^{\circ} 2$ (2011): 305327; Brian Tierney, "Natural Law and Natural Rights Old Problems and Recent Approaches", The Review of Politics 64, n. ${ }^{\circ} 3$ (2002): 389-406. 
evitar los errores típicos en que incurren el economista y el sociólogo. El primero suele olvidar el contexto (la economía no posee dogmas universales, decía Alfred: es un instrumento para alcanzar verdades concretas) y el segundo acostumbra dejar de lado el importante papel de la renta y lo inevitable de la estratificación (queremos igualdad en la escuela para que la desigualdad sea justificada, argüía T.H. Marshall).

Alfred Marshall, en su conferencia "The Future of Working Classes" (1873), ${ }^{18}$ se preguntó si acaso el mercado sería capaz de convertir a todo hombre en un caballero, y arguyó que sí, que el sistema de precios aumentaría el crecimiento, reduciría la jornada y el trabajo manual, y - junto a la obligatoriedad de la enseñanza escolar, algo que pensaba Marshall estaba establecido en interés de los niños y de la sociedadpermitiría, si no la igualdad en todas las esferas de la vida, al menos un resultado parejamente civilizatorio que llevaría a todos a participar de la herencia social. Por caballero él entendía una persona educada, capaz de apreciar los valores del espíritu e integrado a la cultura de su tiempo. De manera más o menos implícita, Alfred Marshall constata una dimensión profunda de la igualdad humana asociada a la compartida pertenencia a una comunidad, a un grupo social; una dimensión común que, le parecía a él, debía desarrollarse.

T.H. Marshall, por su parte, en "Citizenship and Social Class", ${ }^{19}$ también abogó, como es obvio, por la enseñanza obligatoria, aunque, al revés de Alfred, vio en ella el germen de un cambio social más radical. Sugirió que el sistema de precios, o el mercado, requiere que todos los hombres participen de algunas experiencias comunes, entre ellas la educación, para que así la estratificación alcance legitimidad. Y vio en ello el germen de los derechos sociales. Pero esos derechos sociales, a su vez, al fundarse en el bien de la reciprocidad, acabarían modificando el edificio social en su conjunto. Si A. Marshall, el neoclásico, se preocupó de cuánta igualdad educativa proveería el sistema de precios, T.H. Marshall, el sociólogo, estaba preocupado de cuánta y qué igualdad era necesaria para que la desigualdad y la estratificación — que él, como buen sociólogo, sabía inevitable - fueran legítimas. Ambos sabían que

${ }^{18}$ Alfred Marshall, Bristol Selected Pamphlets (University of Bristol Library), disponible en http://www.jstor.org/stable/60244253.

19 T.H. Marshall, The Marshall Lectures (Cambridge, 1949) en Class, Citizenship, and Social Development, del mismo autor (New York: Anchor Books, 1965). 
las sociedades tenían una dialéctica de igualdad y desigualdad, aunque discrepaban en la forma en que ellas se generaban y, en particular, del papel que cabía a la política en todo ello.

Los argumentos que ambos Marshall formulan son especialmente interesantes en el debate contemporáneo sobre el derecho a la educación, porque tanto el marginalista como el sociólogo le asignan a la educación una importancia fundamental a la hora de legitimar los arreglos sociales y advierten en su base un fundamento que no es estrictamente individual. Un hombre educado, advierte Alfred Marshall, tendría conciencia de la importancia social de sus deberes en apariencia más propios, como los que posee hacia sus hijos; sería empático con los demás y procuraría no dañar su bienestar. La educación, en suma, no satisfaría intereses puramente individuales, ejercitaría en bienes sociales importantes para la cooperación ${ }^{20}$ y la extensión de sus beneficios superaría con creces sus costes. ${ }^{21}$ T.H. Marshall, por su parte, piensa que la educación es social porque se trata de un requisito indispensable para la libertad civil y por eso hay un derecho personal a tenerla, pero también un deber público de ejercerla. ${ }^{22}$ Como es obvio, para ninguno de los Marshall la educación era un derecho social en el sentido técnicojurídico de la expresión (que designa, como se vio, habitualmente un título para demandar coactivamente una prestación), sino que su carácter social provenía de su índole, de los bienes que proveía (en el caso de Alfred Marshall) y de la experiencia social que suponía (en el caso de T.H. Marshall). El carácter social del derecho a la educación tenía así un sentido derivado, figurativo, proveniente de su particular índole como práctica social.

Ambos Marshall tenían, a ese respecto, razón.

La educación es una experiencia que, por su misma índole, es pública: supone, en síntesis, acceder a un mundo compartido, a una herencia social sobre la que no existe propiedad y cuyo paradigma es, por supuesto, el lenguaje. ${ }^{23} \mathrm{Y}$ en ella entonces hay dos rasgos que le confie-

${ }^{20}$ A. Marshall, Bristol Selected Pamphlets, 4.

${ }^{21}$ Ibídem, 22.

22 T.H. Marshall, "Citizenship and Social Class", en Class, Citizenship and Social Development, 90.

${ }^{23}$ Véase Pedro Morandé, "Lo público y lo privado en el sistema universitario chileno: visión desde la cultura", en Brunner y Peña, El conflicto de las universidades, 65 y ss. 
ren al derecho a la educación una particularidad especial que obliga, al menos en el sistema escolar, a una distribución igual: a) el primero es que, como sugirió tempranamente Durkheim, se trata, no única pero sí esencialmente, de una práctica mediante la cual la comunidad se reproduce a sí misma, ${ }^{24}$ motivo por el cual no se puede fundar en un interés puramente individual; b) el segundo es que esa práctica, como agrega T.H. Marshall, realiza el igual derecho de todos los miembros de una comunidad a desarrollar diferencias o desigualdades. ${ }^{25}$

Esas características que la educación posee, y que le confieren el carácter de social al derecho a ella, obligan a que el acceso al sistema educativo se independice del mercado. T.H. Marshall pensó por eso en un sistema público uniforme - él escribía cuando las red brick universities estaban en pleno desarrollo - que contribuyera a que todos accedieran a una misma experiencia compartida. De ahí que T.H. Marshall arguyó que pese a que la gratuidad universal acentuaba la diferencia de rentas (como es obvio, si se da el mismo bien a los actuales ricos que a los pobres, los primeros después de la asignación serán más ricos) contribuía a producir bienes que lo justificaban. Es probable, sin embargo, que T.H. Marshall estuviera muy influido por la necesidad de acentuar los rasgos uniformes que requería una sociedad nacional, más que estimular la diversidad que es propia de las sociedades contemporáneas. Si el objetivo era crear una amalgama social que apagara las diferencias culturales que introducían las clases, entonces parece necesario establecer una regla de gratuidad que alcance a todos y un sistema uniforme de provisión. Pero cuando debe compatibilizarse esa amalgama con la expresión de la diversidad de proyectos de vida, es posible igualar la renta para asegurar la igualdad de elección en el acceso. Cuando se atiende a esta diversidad y se admite que la educación también tiene la función de expresarla y permitir que se reproduzca, ya no es necesario tolerar la desigualdad de rentas que la igualdad a ultranza introduce. Asegurar la igualdad de rentas, mediante subsidios, para que todos tengan la oportunidad igual de acceder a un sistema de provisión educativa diversa,

${ }^{24}$ Emile Durkheim, La educación moral (Buenos Aires: Losada, 1997); compárese con A.K.C. Ottaway, "Durkheim on Education", British Journal of Educational Studies 16, n. 1 (1968): 5-16; Robert Prus, "Examining Community Life 'in the Making': Emile Durkheim's 'Moral Education'”, The American Sociologist 42, n. ${ }^{\circ} 1$ (2011): 56-111.

25 T.H. Marshall, "Citizenship and Social Class”, 120. 
evita acrecentar la desigualdad de rentas y, en cambio, también satisface el carácter social que la educación posee.

En otras palabras, el mandato conforme al cual el acceso al sistema educativo debe independizarse del mercado puede ser interpretado de dos maneras diversas: una de ellas consiste en asegurar el acceso de todos a una misma experiencia común, para lo cual hay que asegurar gratuidad total impidiendo que la renta permita eludirla (para lo cual hay que tolerar que la desigualdad de renta en principio se incremente); la otra consiste en asegurar una igualdad de rentas para asegurar el acceso a un sistema de provisión educativa que admita la diversidad. Como se ve, hay razones para pensar que la segunda versión es la correcta y la que mejor se ajusta a las condiciones contemporáneas.

Como explica T.H. Marshall, los derechos sociales se diferencian de los derechos civiles y de los derechos políticos, porque los primeros serían portadores de una nueva forma de concebir las relaciones sociales. Ellos descansarían no en los intereses individuales, sino en una forma de reciprocidad por la que los miembros de una comunidad se reconocen mutuamente el derecho igual a participar de la herencia social. Así concebidos, esos derechos serían incluso anteriores a la irrupción del capitalismo. Su versión inicial se encontraría en las leyes de pobres del siglo XVII, que intentaron sustraer al trabajo del mercado por la vía de asegurar un sustento a quienes no podían trabajar. En ese momento los derechos sociales ya habrían mostrado sus dos notas características: a) su fuente es la pertenencia a una comunidad y b) su propósito es asegurar un salario real ajustado a las necesidades y distinto del precio de mercado que tenía el trabajo. ${ }^{26}$

El derecho a la educación supondría así una demanda de acceso a una experiencia comunitaria, una experiencia dialógica pudiéramos decir, que en vez de inmunizar al individuo contra la injerencia de los demás lo pone en inmediato contacto con ellos, única forma de acceder a un cierta herencia común que está depositada en el lenguaje y en la tradición. Esta reciprocidad, que está a la base del derecho a la educación - consistente, como digo, en sumergir al individuo en una experiencia social, en una experiencia de reciprocidad comunicativa de la que no puede escapar-, es lo que le confiere todas sus particularidades y le

${ }^{26}$ T.H. Marshall, "Citizenship and Social Class”, 86 y ss. 
permite diferenciarlo de la libertad de enseñanza, porque ésta última sí parece ser una mera libertad, un derecho de ejecutar acciones, sobre la base de ciertas reglas, pero sin interferencias no consentidas.

Por supuesto, y como se insistirá luego — ver sección III—, de ese carácter que la educación posee no se sigue que todos los individuos en una sociedad democrática deban ser sometidos a idéntica experiencia social. Algo así tenía sentido en los procesos de construcción de los Estados nacionales, en los que se trataba de construir un público leal a las instituciones del Estado mediante la homogeneización de la cultura; pero en las condiciones contemporáneas es necesario equilibrar contenidos y experiencias comunes con la posibilidad de que las diversas formas de vida puedan también expresarse y reproducirse en la escuela. El derecho a la educación supondría, pues, un acceso igual a una experiencia común; y la libertad de enseñanza, una oportunidad también igual de expresar y reproducir las preferencias familiares. En la ponderación de ambos derechos estaría la clave del diseño del sistema educativo.

En la historia constitucional chilena, sin embargo, el derecho a la educación no ha sido concebido de esa forma.

El caso de La Purísima muestra la primacía que ha recibido en la historia legal chilena la libertad de enseñanza (una extensión de la propiedad como concepto y del peso de la cuna). El debate entre los Marshall, por su parte, muestra hasta qué punto esa primacía es errónea.

Esa forma de concebir el derecho a la educación que, como hemos visto, es predominante en nuestra historia legal - como el derecho de los padres de elegir y el deber del Estado de proveer una oferta mínima- lo desproveería del carácter de derecho social y lo transformaría en un derecho subjetivo a una prestación mínima. ${ }^{27}$

Tanto el derecho a la educación como la libertad de enseñanza han sido concebidos como "derechos subjetivos", es decir, como derechos cuya fisonomía básica se corresponde con la propiedad. El derecho a la educación aparece, en efecto, como el derecho de los padres de elegir el tipo de educación que los padres prefieren para sus hijos, dotado de una garantía mínima provista por el Estado susceptible de ser exigida; y la libertad de enseñanza, por su parte, como un título para ofrecer

${ }^{27}$ Esa interpretación del derecho a la educación, de larga data en la historia constitucional chilena, es funcional al principio de subsidiariedad en su versión más conservadora. 
provisión educativa a los padres. ${ }^{28}$ Esta asimilación del derecho a la educación a un derecho subjetivo, como ha sugerido Atria, ${ }^{29}$ lo priva de su potencial transformador y lo erige en un derecho a demandar servicios educativos mínimos, una suerte de garantía o seguro para cuando la suerte o el destino maltrate al ciudadano, sin establecer ningún principio normativo para orientar el sistema al modo en que, por ejemplo, y en un sentido socialdemócrata, sugirió T.H. Marshall.

\section{III. ¿QUÉ ARREGLOS INSTITUCIONALES SE SIGUEN DE LO ANTERIOR?}

¿Cómo debiera entonces concebirse la relación entre el derecho a la educación y la libertad de enseñanza si, como se acaba de decir, el primero supone una experiencia comunitaria y la segunda, en cambio, no? ¿Qué consecuencias se siguen de las lecciones de los Marshall a la hora de juzgar, e intentar corregir, la trayectoria histórica del sistema en Chile?

Para responder esa pregunta resulta indispensable distinguir los varios problemas que le subyacen.

\section{i) Ante todo, cabe preguntarse cómo concebir los derechos que esas reglas establecen}

En la literatura, como todos saben, los derechos fundamentales son concebidos al menos de dos formas. En una de ellas, un derecho fundamental equivale a una carta de triunfo frente a cualquier argumento utilitarista o relativo al bien de la colectividad como un todo. Decir que usted tiene un derecho de este tipo quiere decir que usted tiene la facultad de ejecutar una acción o abstenerse de ejecutarla, aunque la mayoría

${ }^{28}$ Véase Huneeus, La Constitución, segunda parte, 393; Alejandro Silva Bascuñán, Tratado de derecho constitucional, tomo II, La Constitución de 1925 (Santiago: Jurídica, 1963), 270; José Luis Cea, Derecho constitucional chileno (Santiago: Ediciones UC, 2012), tomo II, 352.

${ }^{29}$ Fernando Atria, Derechos sociales y educación, un nuevo paradigma de lo público (Santiago: Lom, 2014). Atria se inspira en la descripción que hace T.H. Marshall para derivar desde allí un análisis fecundo y original de los derechos sociales que se opone a la explicación estándar centrada en su justiciabilidad. 
se perjudique o esté peor cuando usted lo haga; ${ }^{30}$ en otra concepción, en cambio, un derecho fundamental es un mandato de optimización, una directiva para que el bien se maximice, ponderándolo equilibradamente con otros. En este sentido, decir que usted tiene derecho a hacer algo significa que usted puede exigir que el bien a que el derecho se refiere se le confiera en la máxima medida posible, dentro de las posibilidades jurídicas y reales existentes. ${ }^{31}$

Ahora bien, según veremos de inmediato, el derecho a la educación supone, cuando se atiende a su origen histórico y a sus funciones sociales, una cierta idea del bien de la colectividad como un todo, lo que impide que la libertad de enseñanza pueda ser concebida al modo de una carta de triunfo que puede derrotar cualquier razonamiento agregativo. Si se le concibiera de esa forma, ello supondría cancelar la idea misma de educación. Y es que ella, por su misma índole, es una cuestión pública que supone relaciones de reciprocidad y trato con otros, un bien de relación.

\section{ii) Una vez que se dilucida bajo qué concepción deben ser entendidos} esos derechos, cabe preguntarse si ellos son civiles, políticos o sociales

La libertad de enseñanza, concebida como un espacio o ámbito de inmunidad para emprender proyectos educativos, parece un derecho civil, un derecho de esos que protegen libertades. El derecho a la educación, en cambio, puede ser concebido de dos formas: a saber, como la libertad de escoger a un proveedor educativo sin costo, el derecho en otras palabras a una prestación mínima, o como el derecho a una experiencia formativa común, distribuida igualitariamente. T.H. Marshall argumentaba que la segunda concepción era la correcta. El derecho social, decía Marshall, tiene un fundamento distinto al de los derechos civiles y políticos, ya que él expresa nuestra pertenencia a la comunidad, el derecho que tienen los ciudadanos a participar de la común herencia social. No es un derecho establecido, por decirlo así, sólo en interés del individuo, sino que también existe en interés de la comunidad a la que el individuo pertenece.

${ }^{30}$ Ronald Dworkin, "Rights as Trumps", en Theories of Rights, ed. Jeremy Waldrom (Oxford: Oxford University Press, 1989), 153.

31 Robert Alexy, Teoría de los derechos fundamentales (Madrid: Centro de Estudios Constitucionales, 2002), 86. 
Así lo pone de manifiesto el origen de los sistemas escolares de masas.

Los sistemas escolares de masas nacieron atados a dos ideales normativos de la máxima importancia: uno de ellos fue el ideal meritocrático, el otro fue el de la ciudadanía. Conforme al primero, se abrigó la esperanza de que la escuela pudiera borrar las trazas de la cuna, independizar a los niños de las condiciones en que habían llegado a este mundo y distribuir las oportunidades en base al esfuerzo que cada uno era capaz de hacer. La escuela fue vista así como el punto de partida común, capaz de corregir las desigualdades de la herencia. Conforme al segundo de esos mismos ideales, se vio a la escuela como una primera experiencia ciudadana, como una institución que anticipaba en la trayectoria vital de niños y de jóvenes la vida plural y diversa de la ciudad. Ir a la escuela, separarse de la incondicionalidad del hogar, se pensó, permitiría que los niños y los jóvenes adquirieran las virtudes y los valores que son necesarios para la vida ciudadana, para la vida democrática. De esta manera, la modernidad vio en la escuela la institución que podía hacer más vigorosos, y más reales, los dos ideales que la legitimaban: la igualdad en base al mérito y la vida democrática. Si la sociedad moderna - esa mezcla de capitalismo, Estado y mediatización de la cultura - amenazaba con deteriorar los vínculos y sustituía con rapidez la comunidad (Gemeinschaft) por la sociedad (Gesellschaft), la escuela aparecía, en algún sentido, como una forma de contrarrestar esos males a un nivel más abstracto. Allí donde la escuela se expandiera, se pensó entonces, la suerte de los seres humanos sería menos hereditaria y adscriptiva, y la toma de decisiones tendría más posibilidades de contar con la participación de todos. La escuela fue entonces la institución donde se cruzaban dos ideales normativos que, con toda su ambivalencia, están a la base de la modernidad. ${ }^{32}$

Así entonces el derecho a la educación debe ser establecido como el derecho igual de los ciudadanos a contar con una experiencia cognitiva que les permita desarrollar diferencias y desigualdades.

${ }^{32}$ Carlos Peña, "Escuela y vida cívica", en Aprendizaje de la ciudadanía, contextos, experiencias y resultado, ed. Cristián Cox y Juan Carlos Castillo (Santiago: Ediciones UC, 2015). 
iii) Una vez que se establece como un derecho social, en el sentido que se acaba de indicar, ¿cómo debe organizarse su provisión? ¿A través del Estado o también mediante provisión privada? ¿Podrá derivarse de su carácter social la necesidad de su provisión estatal?

Para responder esta pregunta es útil echar mano a una distinción de Amy Gutmann. Esta autora sostiene que hay dos tipos ideales de sistema educativo. Uno de ellos sería el Estado familia, un Estado que reclama para sí la autoridad educativa exclusiva como una manera de establecer armonía entre el bien social y el individual. ${ }^{33}$ Un tipo de Estado familia sería, por ejemplo, un sistema con provisión estatal única. Al lado de él, continúa Gutmann, existe el Estado de las familias, en el que la autoridad educativa radica ante todo en los padres, quienes pueden organizar y escoger el tipo de educación que prefieren para sus hijos. $^{34}$

¿Qué tipo de institucionalidad educativa — un Estado familia o un Estado de las familias, para repetir las palabras de Gutmann - se sigue del hecho de que la educación es un derecho social de la índole que analiza Marshall?

Hay varias circunstancias que parecen inclinar la balanza en favor de algún tipo de Estado familia.

Desde luego, como lo sugieren múltiples autores (el más notorio, Durkheim, pero también podríamos citar a Dewey y desde luego al propio Marshall), mediante el sistema educativo las sociedades reproducen y configuran lo que pudiéramos llamar su conciencia moral, un puñado de valores y de principios que configuran su identidad. Esta función de la educación se acentuó especialmente en el período de formación de los Estados nacionales (ver al respecto Andy Green) ${ }^{35}$. Durante el siglo XIX, las élites intentaron, mediante la escuela, generalizar códigos comunicativos, valores y una memoria común que hiciera posible a una comunidad política relativamente homogénea: la nación. Fue lo que promovieron los "doctrinarios" en Francia, y lo que el ministro Guizot

${ }^{33}$ Amy Gutmann, Democratic Education (Princeton, NJ: Princeton University Press, 1987), 23.

${ }^{34}$ Ibídem, 28.

35 Andy Green, Education and State Formation (New York: Saint Martin Press, 1990). 
llamó el "gobierno de las mentes" indispensable para la legitimidad de la vida social. ${ }^{36}$

El sistema escolar o educacional también tiene funciones distributivas. Mediante la educación las sociedades intentan corregir las arbitrariedades de la cuna y del azar natural. Este es un viejo tema que se encuentra ya en Platón (en la República, Platón sugiere separar a los niños de las familias para así suprimir las ventajas de la cuna). La escuela es una institución que se funda en el principio de que la repartición de méritos y de oportunidades debe estar basada en el desempeño, borrando, en lo posible, las condiciones de origen. En otras palabras, la promesa de la educación es que el destino de los nuevos miembros de la sociedad dependa de su voluntad de logro.

La educación también cumple funciones estrechamente vinculadas con la ciudadanía. Las competencias que son necesarias para el ejercicio de la ciudadanía (una experiencia cognitiva común, el uso de un mismo código comunicativo) y las virtudes que hacen a un buen ciudadano (disposición al diálogo, a dejarse persuadir por buenas razones) son claves para el funcionamiento de la democracia. Cómo sean los ciudadanos del futuro y cuán cohesionada sea nuestra comunidad política son cuestiones que dependen del sistema escolar que tengamos hoy. Cuando un niño ingresa al colegio - $-\mathrm{y}$ aprende a participar de una experiencia común no guiada directamente por la familia - empieza a incorporarse a la ciudad, a la polis.

Todas esas funciones parecen dar la razón a T.H. Marshall cuando enfatiza que es la sociedad la principal interesada en la educación, más que el individuo. Razón de sobra, al parecer, para inclinarse, en principio, por alguna forma de Estado familia.

Pero hay otras funciones que la educación cumple, que aconsejan relativizar esa conclusión e inclinan la balanza hacia una figura más cercana al Estado de las familias.

Desde luego, la educación crea y fortalece eso que suele llamarse capital humano, que es un bien predominantemente privado. Es verdad que hay correlaciones entre crecimiento económico y nivel educacional de los países y que ello hace del capital humano un bien en parte público; pero también es cierto que quien internaliza ese capital es el primero

${ }^{36}$ Véase Charles Glenn, El mito de la escuela pública (Madrid: Encuentro, 2006), 61; compárese con Pierre Rosanvallon, La legitimidad democrática: imparcialidad, reflexividad, proximidad (Buenos Aires: Manantial, 2009), 263. 
que se beneficia con él. Por eso, como incluso el propio T.H. Marshall sugiere, la educación es también un principio de desigualdad o de estratificación social.

A lo anterior se suma que en las sociedades contemporáneas — que reconocen la libertad de religión y de conciencia - el sistema educativo también cumple la función de reproducir el modo o forma de vida que los padres estiman mejor para sus hijos. Las sociedades democráticas son sociedades diversas, heterogéneas, y la escuela es también el lugar mediante el cual los diversos grupos y formas de vida intentan reproducir sus valores. La pluralidad de una sociedad democrática — religiosa o de otra índole - también se expresa en el sistema escolar.

Todas esas funciones que la escuela cumple en las sociedades contemporáneas aconsejarían estimular una provisión mixta con predominancia pública o estatal, entre la que las familias pudieran escoger. La predominancia pública o estatal permite asegurar ciertas características que, si no coinciden estrictamente con la experiencia común de que habla Marshall, sí permiten asegurar el logro de ciertos bienes comunes, como, por ejemplo, el currículum nacional, el aseguramiento de la calidad, la realización de ciertas prácticas en la comunidad educativa. Y la existencia de un sistema mixto asegura la posibilidad de elección.

iv) Establecido lo anterior - es decir, una vez que se concluye que un sistema mixto resulta razonable - ¿es admisible el uso de subsidios en el sistema educativo?

T.H. Marshall advirtió que la tarea de los derechos sociales no era exactamente igualar la renta sino el estatus de los ciudadanos, algo que sólo podía alcanzarse por la vía de someterlos a una misma experiencia social. De ahí entonces que él tenía razones para rechazar en materia educativa el uso predominante del subsidio. La transferencia de subsidios (lo que él llamaba "igualar la renta") no se traduce en la igualación del estatus o de la experiencia. Esto último, sugirió Marshall, sólo se alcanzaría por la vía de instaurar servicios gratuitos y universales. Es verdad, dijo, que los servicios universales aumentan la diferencia de renta (puesto que los más ricos liberan recursos para destinar a otros fines), pero proveen una misma experiencia nueva para todos. ${ }^{37}$ Esta solución de Marshall

${ }^{37}$ T.H. Marshall, "Citizenship and Social Class", 112 y 113. 
exigiría igualar la provisión educativa más allá de lo que se alcanza con un currículum nacional, instalando un sistema de provisión pública lo más uniforme e integrado posible y con financiamiento a la oferta.

Lo que sugiere Marshall es algo que hoy suele repetirse una y otra vez: no basta con igualar las rentas, por ejemplo mediante subsidios, para que la educación realice el ideal de igualdad: es imprescindible que la educación se asemeje a una experiencia universal común. La razón de esto, argüía Marshall, es que la educación incentiva a las personas hacia el interés público y les permite compartir un mismo ideal de comunidad. De ahí que, en su particular lenguaje, Marshall sostuviera que los derechos sociales - y el de educación para él era uno de los más característicos - estaban destinados a cambiar la totalidad del edificio social (o, como se prefiere decir hoy, cambiar el paradigma social en su conjunto).

Pero, como ya vimos, Marshall abogaba por un rechazo del subsidio porque él pensaba que la educación tenía, ante todo, la tarea de proporcionar a todos la oportunidad de participar de una misma experiencia comunitaria. De ser así, él tenía toda la razón al sostener que era mejor proveer de una misma experiencia, aun al precio de desequilibrar la renta al transferir recursos a los más ricos. Sin embargo, como ya fue explicado, esa descripción de Marshall parece muy simple (incurre en el vicio que Wittgenstein llamaba de la "dieta unilateral"), puesto que olvida que hoy la educación también equivale en parte a un bien privado y debe ser sensible a la diversidad de formas de vida. De ahí entonces que un sistema mixto, con igualación de rentas, es perfectamente compatible con el carácter social del derecho, puesto que su titularidad a) deriva de la membresía comunitaria y b) su acceso se independiza de la renta de mercado.

\section{v) Una vez que se ha logrado caracterizar tanto la fisonomía} institucional del derecho, como la forma de su financiamiento, lo que cabe preguntarse es si el derecho a la educación y a la libertad de enseñanza, asi caracterizados, se extienden a todo el ciclo educativo o sólo deben alcanzar a la enseñanza obligatoria.

T.H. Marshall puede, de nuevo, ayudar a resolver este punto.

Marshall sugirió que el sistema educativo procuraba asegurar una igual oportunidad de ser desigual. La fórmula, de apariencia rocambo- 
lesca, indica el hecho fundamental de que la escuela es meritocrática, es decir, distribuye recursos y oportunidades personales en base al desempeño alcanzado; así es una desigualdad, pudiéramos decir, justificada.

La precedente característica del sistema escolar explica, por su parte, que el sistema de educación superior sea selectivo y de ingreso meritocrático. Esto es, los lugares que aseguran un puesto alto en la escala invisible del prestigio y del poder no están a disposición de todos sino, en términos generales, de los de mayor rendimiento. Si en el sistema escolar hay un derecho a la participación igual, ello no ocurre en el sistema de educación superior, donde el derecho alcanza nada más que a la apreciación imparcial del propio mérito.

Lo anterior se condice, además, con el hecho de que las instituciones de educación superior, particularmente las universidades, se originan en la modernidad con una inspiración distinta a la escuela. Si la escuela nació para realizar los ideales de la ciudadanía y la meritocracia, las universidades nacieron para apoyar los objetivos nacionales (como ocurre con el modelo napoleónico) o para el cultivo de la ciencia (como ocurre con el modelo humboldtiano).

Esta diferencia fundamental entre el sistema de escolaridad obligatoria y la educación superior se ha tendido a olvidar en el debate público, tratándose a las instituciones de uno y otro sector de manera más o menos indistinta. Se trata de un simple error derivado, sin duda, del hecho de que al no existir el principio meritocrático en el sistema escolar, la selectividad de la educación superior aparece como injustificada. Pero si, como se ha sugerido, el acceso a la educación obligatoria se trata como un derecho social en el preciso sentido que aquí se ha indicado, no parece haber obstáculos normativos para concebir un sistema de educación superior que asegure el acceso bajo el principio de igualdad de rentas, selectivo y diverso.

Abdón Cifuentes, el ministro que debió renunciar como consecuencia del escándalo que desató el colegio La Purísima, alega en sus memorias que la suya fue una batalla por evitar que el Estado se hiciera del monopolio de la educación, puesto que si lo lograba la libertad de religión y de conciencia se harían sal y agua. Sus detractores, en tanto, pensaron que, si se toleraba la libertad de enseñanza a ultranza, la cohesión social y el futuro de la república estarían en peligro.

Esos argumentos no son distintos de los que se esgrimen hoy, y es que, como enseña la historia, el campo educativo es el campo de batalla 
por el control de la esfera pública, ese ámbito donde se moldea la vida en comunidad. Y es por eso quizá que, a diferencia de lo que ocurre con los derechos vinculados a la autonomía individual, el derecho a la educación y la libertad de enseñanza requieren una definición política de base, una respuesta a la pregunta que según Platón estaba a la base de todas las demás: ¿cómo es que queremos vivir? ¿Queremos vivir en una sociedad contributiva, una en la que cada uno recibe, en materia de salud, educación o vivienda, tanto como aportó, o, en cambio, preferiremos vivir en una sociedad de prestaciones universales, es decir, una en la que cada uno recibe cierto tipo de bienes en razón, simplemente, de su pertenencia a la comunidad política? En la respuesta a esta pregunta está la fisonomía definitiva que decidamos conferir al derecho a la educación.

\section{BIBLIOGRAFÍA}

Ackerman, Bruce. We the People: Transformations, vol. 2. Cambridge, Mass: Harvard University Press, 1998.

Alexy, Robert. Teoría de los derechos fundamentales. Madrid: Centro de Estudios Constitucionales, 2002.

Archer, Margaret. Social Origins of Educational Systems. Nueva York: Routledge, 2013.

Atria, Fernando. Derechos sociales y educación, un nuevo paradigma de lo público. Santiago: Lom, 2014.

Barros Arana, Diego. Mi destitución. Apuntes para la historia del Instituto Nacional. Santiago: Imprenta El Ferrocarril, 1873.

Brunner, José Joaquín. "La república educacional 1910-2010”. En El Chile del bicentenario, coordinado por Maximiliano Figueroa y Manuel Vicuña. Santiago: Ediciones UDP, 2008.

Brunner, José Joaquín \& Carlos Peña, eds. El conflicto de las universidades: entre lo público y lo privado. Santiago: Ediciones UDP, 2011.

Cea, José Luis. Derecho Constitucional Chileno, tomo II. Santiago: Ediciones UC, 2012.

Cifuentes, Abdón. Memorias. Santiago: Nascimento, 1933.

Durkheim, Emile. La educación moral. Buenos Aires: Losada, 1997.

Dworkin, Ronald. "Rights as Trumps". En Theories of Rights, editado por Jeremy Waldrom. Oxford: Oxford University Press, 1989.

Encina, Francisco Antonio. Historia de Chile. Desde la prehistoria hasta 1891. Santiago: Nascimento, 1970.

Glenn, Charles. El mito de la escuela pública. Madrid: Encuentro, 2006. 
Green, Andy. Education and State Formation. New York: Saint Martin Press, 1990.

Gutmann, Amy. Democratic Education. Princeton NJ: Princeton University Press, 1987.

Hohfeld, Wesley Newcomb. "Some Fundamental Legal Conceptions as Applied in Judicial Reasoning". The Yale Law Journal 23 (noviembre, 1913).

- "Fundamental Legal Conceptions as Applied in Judicial Reasoning". The Yale Law Journal 26 (junio, 1917).

Huneeus, Jorge. La Constitución ante el Congreso o sea comentario positivo de la Constitución Chilena. Santiago: Imprenta de Los Tiempos, 1880.

Kelsen, Hans. Teoría pura del derecho. Traducido por Roberto J. Vernengo. México: Porrúa, 1991.

Kivisto, Peter. "T.H. Marshall revisited: Neoliberalism and the Future of Class Abatement in Contemporary Political Discourse about the Welfare State". International Review of Modern Sociology 33, n. ${ }^{\circ} 1$ (2007): 1-19.

Labarca, Amanda. Historia de la enseñanza en Chile. Santiago: Universitaria, 1939.

Letelier, Valentín. Filosofia de la educación. Santiago: Cervantes, 1912.

Marshall, Alfred. "The Future of Working Classes". En Bristol Selected Pamphlets. University of Bristol Library. http://www.jstor.org/stable/60244253.

Marshall, T.H. Class, Citizenship, and Social Development. New York: Anchor Books, 1965.

Morandé, Pedro. "Lo público y lo privado en el sistema universitario chileno: visión desde la cultura”. En Brunner \& Peña, El conflicto de las universidades.

Ottaway, A.K.C. "Durkheim on Education". British Journal of Educational Studies 16, n. ${ }^{\circ} 1$ (1968): 5-16.

- "The Educational Sociology of Émile Durkheim". The British Journal of Sociology 6, n. 3 (1955): 213-227.

Peña, Carlos. "Escuela y vida cívica". En Aprendizaje de la ciudadanía, contextos, experiencias y resultado, editado por Cristián Cox y Juan Carlos Castillo. Santiago: Ediciones UC, 2015.

Prus, Robert. "Examining Community Life 'in the Making': Emile Durkheim's 'Moral Education"”. The American Sociologist 42, n. ${ }^{\circ} 1$ (2011): 56-111.

Rosanvallon, Pierre. La legitimidad democrática: imparcialidad, reflexividad, proximidad. Buenos Aires: Manantial, 2009.

Salas, Darío. El problema nacional. Santiago: Universo, 1917.

Sarmiento, Domingo Faustino. De la educación popular. Santiago: Biblioteca Fundamentos de la Construcción de Chile, 2009.

Seagrave, Adam. "How Old Are Modern Rights? On the Lockean Roots of Contemporary Human Rights Discourse". Journal of the History of Ideas 72, n. ${ }^{\circ} 2$ (2011): 305-327.

Serrano, Sol, Macarena Ponce de León \& Francisca Rengifo. Historia de la educación en Chile (1810-2010), tomo II, La educación nacional (18801930). Santiago: Taurus, 2012. 
Silva Bascuñán, Alejandro. Tratado de derecho constitucional, tomo II, La Constitución de 1925. Santiago: Jurídica, 1963.

Stuven, Ana María. "Estado docente y libertad de enseñanza: el conflicto por el control del espacio público chileno en el siglo XIX". En Brunner \& Peña, El conflicto de las universidades.

Tierney, Brian. Liberty and Law. The Idea of Permissive Natural Law, 1100-1800. Washington: Catholic University of America Press, 2014.

—. "Natural Law and Natural Rights Old Problems and Recent Approaches". The Review of Politics 64, n. 3 (2002): 389-406.

Tönnies, Ferdinand. Gemeinschaft und Gesellschaft (1887). Traducido por José Rovira Armengol como Comunidad y sociedad (Buenos Aires: Losada, 1947).

Villey, Michel. Estudios en torno a la noción de derecho subjetivo. Valparaíso: Ediciones Universitarias de Valparaíso, 1976. EP 